\title{
Spanish validation and factor structure of the Prenatal Distress Questionnaire Revised
} (NuPDQ)

Borja Romero-Gonzalez ${ }^{1,2}$, Colin R. Martin ${ }^{3}$, Rafael A. Caparros-Gonzalez ${ }^{*}$, Juan M. QuesadaSoto $^{2}$, Maria Isabel Peralta-Ramirez ${ }^{1}$

${ }^{1}$ Department of Personality, Assessment and Psychological Treatment, University of Granada, Granada, Spain

${ }^{2}$ Brain, Mind and Behavior Research Center (CIMCYC), Faculty of Psychology, University of Granada, Granada, Spain

${ }^{3}$ Faculty of Health Sciences, University of Hull, HU6 7RX, UK

${ }^{4}$ Nursing Department. Faculty of Health Sciences, University of Granada, Spain.

\section{Corresponding author:}

Rafael A. Caparros-Gonzalez

Nursing Department. Faculty of Health Sciences, University of Granada, Spain Av. de la Ilustración, 60, 18016 Urb. los Vergeles, Granada, Spain rcg477@ugr.es

Funding Sources: This work was supported by the by the Frontier Project "A-CTS-229UGR18" of the Ministry of Economy, Knowledge, Business and University of the Junta de Andalucía, co-supported by funds/European Regional Development Fund (ERDF) - a way to build Europe. Besides, Dr. Borja Romero-Gonzalez has been awarded with an individual research grant (Spanish Ministry of Economy, Industry and Competitiveness, FPI Program, reference number BES-2016-077619)

Disclosure of interest: The authors report no conflict of interest

Acknowledgements: Thank you to every pregnant woman who joined and completed our study. This study is a part of a Doctoral Thesis of Dr. Borja Romero-Gonzalez. 


\begin{abstract}
Background: Due to an absence of maternal stress being measured in routine prenatal care by clinicians, prenatal stress has become a serious problem which is associated with poorer obstetric outcomes, as well as a worst maternal and infant health. For that reason, the aim of this study was the translation, validation and adaptation of Prenatal Distress Questionnaire Revised (NuPDQ) in a Spanish sample. Methods: Three-hundred and seventy-one pregnant women were assessed using the NuPDQ, the Prenatal Distress Questionnaire (PDQ), Perceived Stress Scale (PSS) and the Connor-Davidson Resilience Scale (CD-RISC). The NuPDQ were translated into a Spanish by the backtranslation method and administered to participants. Results: A confirmatory factor analysis revealed the established unidimensional structure to be a poor fit to data with the Spanish version. An exploratory factor analysis suggested a five-factor structure with 14-item. The instrument had good reliability, convergent and discriminant validity psychometric properties. Conclusions: The five-factor 14-item NuPDQ is useful to assess pregnancyspecific stress in Spanish pregnant women. It may be appropriate to use this instrument in order to identify pregnant women with high pregnancy-specific stress and try to prevent negative consequences derived from those high levels.
\end{abstract}

Keywords: pregnancy, stress, concerns, factor structure 


\section{Introduction}

Pregnancy is a stressful event in a woman's life, the impacts of such stress having implications for the woman themselves or their baby (Duthie \& Reynolds, 2013). A number of studies have demonstrated that stress during pregnancy is not the same as general population stress, so it has been called as pregnancy-specific stress (Alderdice et al., 2012; Lobel et al., 2008).

On one hand, pregnancy-specific stress is comprised of childbirth and medical complications worries, body changes worries, concerns about future baby health or the ability to become a mother (Alderdice et al., 2012). On the other hand, physiological activation and consequences are different from general stress, being related to more potential negative pregnancy outcomes (Alderdice \& Lynn, 2009; DiPietro et al., 2002; DiPietro et al., 2004; Lobel \& Dunkel Schetter, 2016).

Pregnancy-specific stress has been related to impoverished postpartum maternal mental health, higher postpartum depression risk and the inability to care the newborn (CaparrosGonzalez et al., 2017; Field, 2010; Robertson et al., 2004). Further, there are some new born negative outcomes associated with higher pregnancy-specific stress levels, such as premature birth, low weight at birth and a poorer infant neurodevelopment (GraignicPhilippe et al., 2014; Lobel et al., 2008; Roesch et al., 2004).

Consequently, it is important to use assessment tools to identify pregnancy-specific stress, as generic stress assessment tools will not reflect endocrine, psychological and individual characteristics of pregnancy (Nast et al., 2013).

Two assessment measures have been widely used to evaluate pregnancy-specific stress due to their generally acceptable psychometric characteristics, these being the Prenatal 
Distress Questionnaire (PDQ; Yali \& Lobel, 1999) and its revised version, Prenatal Distress Questionnaire Revised (NuPDQ; Lobel, 1996; Yali \& Lobel, 2002). However, only the PDQ is already validated for its use in Spain (Caparros-Gonzalez et al., 2019).

Despite the fact that NuPDQ was originally designed to be used as an interview, it has invariably been used as a self-report instrument, reporting a good reliability index in its original version (Coussons-Read et al., 2012; Lobel et al., 2008; Magriples et al., 2008; Staneva et al., 2016). It has been used in a wide range of studies, and it is considered as an appropriate instrument due to its reliability and convergent, concurrent, and predictive validity (Ibrahim \& Lobel, 2019). To the best of our knowledge, only one study shown the factor structure of the NuPDQ, as a unidimensional instrument (Yuksel et al., 2011).

The aim of this research was the translation, adaptation and validation of NuPDQ in a Spanish sample of pregnant women.

\section{Material and Methods}

\section{Participants}

Three-hundred and eighty-six women were recruited from Health Centres from all around XXX (XXX masked for review) between $1^{\text {st }}$ October 2017 and $13^{\text {th }}$ September 2018.

Inclusion criteria were being pregnant, over 18 years old and being born in Spain. As exclusion criteria were having medication treatment, any medical or psychological condition or being a high-risk pregnancy. 


\section{Instruments}

Prenatal Distress Questionnaire Revised (NuPDQ; Lobel, 1996; Yali \& Lobel, 2002). Original version contains 17 items in a Likert scale $(0=$ not at all; $2=$ very much $)$ and another item with a dichotomic response (yes or no). Every item asked `Are you feeling bothered, upset, or worried at this point in your pregnancy`about pregnancy issues, such as maternal and baby health, body changes, abilities to take care of the baby, etc. Despite being developed to be used in different points of pregnancy ( 9 items for the entire period, 3 more for the second trimester and 5 more for the third trimester), it has been widely used as an integrated single measure of prenatal distress. In that way, the instrument offers more information than using only the items of each trimester. Besides, it has good psychometric properties $(0.82>\alpha<0.88)$ (Alderdice et al., 2012; Lobel et al., 2008; Yali \& Lobel, 1999; Yali \& Lobel, 2002).

The following instruments were used to evaluate convergent and discriminant validity:

-Prenatal Distress Questionnaire (PDQ; Yali \& Lobel, 1999; Caparros-Gonzalez et al., 2019) has been used to assess pregnancy-specific stress. It assesses specific worries and concerns that pregnant women experience about labour, medical problems, physical symptoms, childbirth, relationships, body changes, and the baby's health using a 12-item scale scored with a 5 -point Likert scale $(0=$ none at all; $4=$ extremely $)$. The Cronbach's alpha reliability coefficient for the Spanish version is $\alpha=0.74$.

-Perceived Stress Scale (PSS; Cohen et al., 1983; Remor, 2006) was used to assess general stress during the last month. It has 14 items scored using a 5-point Likert scale from 0 (never) to 4 (very often). The Cronbach's alpha reliability coefficient of the Spanish version is $\alpha=0.81$. 
-Connor-Davidson Resilience Scale (CD-RISC; Connor \& Davidson, 2003; García-León et al., 2019). It has 25 items with a Likert-type response format, punctuated by 0 ('not at all') to 4 ('almost always'). The scale is in the range of 0 to 100 , and higher scores indicate a higher level of resilience. The Cronbach's Alpha reliability coefficient of the Spanish version is $\alpha=0.86$.

\section{Procedure}

The translation of NuPDQ into Spanish was undertaken using the backtranslation method according to international guidelines for cross-cultural adaptations of questionnaires (Epstein et al., 2015; Martin \& Savage-McGlynn, 2013). Firstly, the original version was translated into Spanish by two researchers with a proficient level in English. Thereafter, another researcher with proficient levels in both English and Spanish and who was unconnected to the research, translated the scale into English. An expert team in perinatal health was consulted to check if translation was grammatically and semantically equivalent to the original questionnaire. No variability was found among versions.

One item was identified as problematic within the Spanish context: 'Are you feeling bothered, upset, or worried at this point in your pregnancy about paying for your medical care during pregnancy? The Spanish healthcare system is free of charge, for that reason this item was no sense for Spanish pregnant women. For that reason, it was removed and not include in Spanish version of the NuPDQ.

A pilot study $(\mathrm{N}=10)$ was undertaken to obtain feedback about comprehension and interpretation. No further issues were identified and the final version was prepared for data capture. 
Participants were informed about the study when attending an antenatal appointment with their midwives. Following enrolment into the study and obtaining informed consent, the questionnaires were administered.

This study met the ethical standards established by the Declaration of Helsinki (revised in Fortaleza, Brazil, 2013) and was reviewed and approved by the Ethics Committee for Human Research at the University of XXX (reference number XXX) and the Research Ethics Committee of the public health service in XXX.

\section{Statistical analysis}

A conventional route to psychometric evaluation was undertaken using known-groups discriminant validity analysis with pregnancy status (pregnant previously yes/no) as the dichotomous independent variable, internal consistency evaluation using Cronbach's coefficient alpha and convergent and divergent validity determination by evaluation against relevant elements of the measures outlined earlier. The factor structure of the NUPDQ was evaluated using confirmatory factor analysis (CFA) specifying a singlefactor (uni-dimensional) model. In the event of poor or inadequate model fit under CFA, a post-hoc exploratory factor analysis (EFA) would be undertaken to determine factor structure using maximum-likelihood estimation and oblimin rotation.

\section{Results}

\section{Sample description}

From the three-hundred and eighty-six women which were recruited to the study, a total sample of three-hundred and seventy-one had complete NuPDQ data ( $N=371)$. Examination of the dataset revealed one multivariate outlier based on NuPDQ data and 
this case was removed from the dataset thus the final data set was $\mathrm{N}=370$ for analysis. The mean age of participants was $32.36(\mathrm{SD}=5.10)$ years. Descriptive information is shown in Table 1.

\section{TABLE 1 ABOUT HERE}

\section{Summary of measures}

The mean score of the NuPDQ was $13.23(\mathrm{SD}=6.03)$ with a minimum score of 0 and a maximum score of 32. Internal consistency of the NuPDQ was 0.82 . There was no evidence of significant skew or kurtosis in the NuPDQ total score $(0.24,-0.52$ respectively). The mean score of the PDQ was $16.53(\mathrm{SD}=7.10)$, the mean score of the PSS was $26.43(\mathrm{SD}=8.15)$ and the mean score of the CD-RISC was $26.85(\mathrm{SD}=6.65)$.

\section{Correlational analysis}

Pearson's $r$ correlations between the NuPDQ total score and PDQ, PSS and CD-RISC total scores are shown in Table 2. Correlations between the NuPDQ total score and all other measures were all highly statistically significant $(p<0.001)$ and in the anticipated direction.

\section{TABLE 2 ABOUT HERE}

\section{Factor analysis}

Confirmatory factor analysis of the unidimensional model of the NuPDQ with maximumlikelihoods estimation revealed a poor fit to the data, chi-square $=487.68(\mathrm{df}=119.00) p$ $<0.001$, root mean squared error of approximation $($ RMSEA) $=0.09$, comparative fit index $(\mathrm{CFI})=0.72$. Adopting the weighted least squares with means and variances 
(WLSMV) estimation method to accommodate the ordered categorical characteristics of NuPDQ items within the CFS had little impact in improving model fit, chi-square = $518.82(\mathrm{df}=119.00) p<0.001, \mathrm{RMSEA}=0.10, \mathrm{CFI}=0.83$.

\section{Post-hoc exploratory factor analysis}

Given the poor fit to data of the anticipated single-factor model of the NuPDQ, a posthoc exploratory factor analysis was undertaken. A parallel analysis suggested the potential of a five-factor solution though only one factor had an eigen value $>1$ and the screen plot also indicated a single factor solution. Given the previously acknowledged poor-fit of a single-factor solution an alternative five-factor solution based on the parallel analysis was run as a post-hoc EFA under maximum-likelihood estimation with oblique rotation assuming correlated factors. The five-factor solution revealed a good fit to the data, RMSEA $=0.04$ and $\mathrm{CFI}=0.97$ and $39 \%$ of the variance explained. The item-factor loading are summarised in Table 3. and reveal clear item-factor differentiation for most items with the exception of items 1 . and 17. where these items did not load on any factor and item 10. which was split between factors 1 . and 5. These three items were thus removed and re-examination of model fit statistics revealed excellent fit, RMSEA $=0.04$ and $\mathrm{CFI}=0.99$ with $47 \%$ of the variance explained. Internal consistency of the remaining 14-items was 0.81 . The same five-factor model was run for trimester two data $(\mathrm{N}=135)$ and revealed excellent fit to the data (RMSEA $=0.01$ and CFI $=0.99$ with $49 \%$ of the variance explained). Similarly, examination of the five-factor model for trimester three data $(\mathrm{N}=160)$ revealed again excellent fit to data $(\mathrm{RMSEA}=0.01$ and $\mathrm{CFI}=0.99$ with $50 \%$ of the variance explained). Unfortunately, there was insufficient participant numbers in trimester one to run the five-factor model with confidence. 


\section{TABLE 3 ABOUT HERE}

\section{Items description and factors name}

According to every item description, every factor has renamed in order to have sense when using it in studies. Items allocated in factor 1 assess worries about delivery and pain, items in factor 2 share worries about maternal health and the ability to be able to take care of family during pregnancy, items in factor 3 describe worries about taking care of the baby. As for items in factor 4, they assess worries about changes resulting from pregnancy. Finally, factor 5 explore worries about unexpected issues of pregnancy (preterm birth) and incontrollable issues (get a good quality of medical care). Items description and factors name are described in Table 4 . We note that factor 1 , factor 3 and factor 5 comprise two items only (factor 1 inter-item correlation $r=0.62$, factor 3 interitem correlation $r=0.60$, factor 5 inter-item correlation $r=0.33$ ).

\section{TABLE 4 ABOUT HERE}

\section{Correlations between sub-scales}

The five sub-scales extracted from the EFA comprise three sub-scales comprising two items each (sub-scales 1, 3, 5) and two sub-scales comprising four items each (sub-scales 2,4). All correlations were positive and highly statistically significant $(\mathrm{p}<0.001)$. The correlations between these EFA-derived sub-scales is shown in Table 5.

\section{TABLE 5 ABOUT HERE}

\section{Known-group discriminant validity}


Comparison between the 14-item EFA-derived NuPDQ total score and EFA-derived subscales as a function of previous pregnancy status are shown in Table 6. Significantly higher sub-scale scores were observed for those who had a previous pregnancy on subscales 1 . and 4. only.

\section{TABLE 6 ABOUT HERE}

\section{Correlations between sub-scales and PDQ, PSS and CD-RISC total scores.}

Pearson's $r$ correlations between the 14-item EFA-derived NuPDQ total score and EFAderived sub-scales and PDQ, PSS and CD-RISC total scores are shown in Table 7. All correlations were highly statistically significant $(p<0.001)$ and in the anticipated direction with the exception of sub-scale 3 and CD-RISC total score $(p=0.17)$ and sub-scale 5 and CD-RISC total score $(p=0.01)$.

\section{TABLE 7 ABOUT HERE}

\section{Discussion}

Due to the increasing importance of accurate assessment of pregnancy-specific stress, and the inexistence of a Spanish assessment tool as the NuPDQ, the aim of this research was the translation, adaptation and validation of the NuPDQ into Spanish. Moreover, it was intended to analyse the unidimensional factorial structure of the Turkish version (Yuksel et al., 2011) to check if the Spanish version was consistent with a unidimensional measurement model.

Firstly, CFA demonstrated poor model fit against data for the unidimensional model, contrary to the Turkish version proposed by Yuksel et al. (2011). It is important to highlight that between Turkish and Spanish samples there are many cultural differences 
(Gonzalez-Mesa et al., 2018). This may explain, at least to a degree, the inconsistencies in factor structure between Spanish and Turkish versions of the NuPDQ.

Post-hoc EFA revealed that a five-factor model was the most appropriate fit to data, with accompanying good model fit characteristics. Nevertheless, some items had to be removed from this five-factor model. Specifically, item 1: 'Are you feeling bothered, upset, or worried at this point in your pregnancy about taking care of a new born baby? which did not fit in any factor. One plausible explanation is that there were more multiparas in our sample, which could influence in the fact that the item could not be allocated into any factor. Besides, this item is too general to fit in any factor, as the words 'taking care' could mean a wide range of aspects, which could be economical, psychological or even social support (Gurman \& Becker, 2008). Item 17 was removed too, the item content itself could explain the reason why it had to be removed, as it was the only dichotomic item in the questionnaire (Are there other things that you are bothered, upset, or worried about that have to do with your pregnancy, the birth, or the baby?`), being very ambiguous (Lobel, 1996; Yali \& Lobel, 2002). Finally, item 10 ('Are you feeling bothered, upset, or worried at this point in your pregnancy about whether you might have an unhealthy baby?) could be allocated into factors 1 and 5, so it was removed from the factorial structure. Similar to the factorial structure of their Spanish previous version, the PDQ (Caparros-Gonzalez et al., 2019) which also revealed that this item did not perform well. Confidence in the five-factor model was observed in relation to excellent fit to data for this model when trimester two and trimester three data was examined separately. A limitation of the study was that there was insufficient participant numbers to explore the fit to data of this model in the first trimester, therefore we would recommend further investigation of this model in further research with sufficient 
participant numbers in the first trimester to undertake this analysis. We note also that a further limitation is that our criteria for item rejection was solely based on measurement characteristics within the EFA and acknowledge that other approaches, for example a content analysis or expert panel review may have yielded an alternative profile of both item rejection and item sub-scale inclusion.

The14-item NuPDQ was observed to have good psychometric properties as a multidimensional measure and can be recommended for use in Spanish pregnant women in order to assess pregnancy-specific stress, just as it has been used in another countries (Ibrahim \& Lobel, 2019).

Reliability of the NuPDQ is in line with those found by another authors, which have varied from .79 to .88 (Staneva et al., 2017; Rosenthal \& Lobel, 2018) and superior to the Spanish PDQ which has a reliability index of .74 (Caparros-Gonzalez et al., 2019).

The NuPDQ, comprises 14 items allocated into 5 factors or sub-scales, which are: 'worries about delivery (items 4 and 11)'; 'worries about own health and pregnancy' (items 2, 3, 7 and 12); 'worries about taking care of the baby' (items 14 and 15); 'worries about physical, social and economic changes` (items 5, 9, 13 and 16); and 'worries about unexpected and incontrollable issues of pregnancy` (items 6 and 8). It should be noted that since three of the sub-scales contain just two items, further research would be valuable to evaluate with greater scrutiny the reliability of these sub-scales and if augmentation with additionally generated items may be required. The sub-scales would thus appear appropriate to assess pregnancy-specific stress as a multi-dimensional rather than a unitary construct, thus encompassing by concerns about the management and significance of physical symptoms, body changes, social changes, concerns about labour 
and delivery, parenting, the health of their foetus and fear of medical complications (Alderdice et al., 2012; Caparros-Gonzalez et al., 2019; Romero-Gonzalez et al., 2018; Romero-Gonzalez et al., 2019).

Discriminant validity evaluation of the NuPDQ revealed differences in sub-scales of 'worries about delivery' and 'worries about physical, social and economic changes', having multiparous pregnant women more concerns. Previous pregnancies may reduce concerns about maternal and foetal health, given more importance to those concerns about changes that could bring the birth of a second (or more) baby, which needs a different psychological and lifestyle adaptation than having the first child (Volling, 2012).

Finally, there is a strong relation between every NuPDQ subscale and the PDQ and perceived stress, which manifests once again the usefulness of the questionnaire. Only with the resilience, the relation was not the expected one with the subscale of 'worries about taking care of the baby`. Even when resilience has been proved to be a protective factor during pregnancy, it seems not to be associated by this kind of concerns (GarciaLeon et al., 2019).

The present study has some limitations, as the NuPDQ has been validated in its questionnaire form, so it is not possible to know the psychometric properties of its interview version. Another limitation is that we have used the same sample to perform the CFA, so it would be interesting to confirm the factorial structure of the NuPDQ using another sample of pregnant women. Moreover, considering the exclusion criteria of having a high-risk pregnancy, this tool should only be used to assess prenatal distress in low-risk pregnant women. For that reason, future research should address the pregnancy- 
specific stress in high-risk pregnancies, as it could be different from low-risk pregnancies (Caparros-Gonzalez et al., 2019).

In conclusion, the NuPDQ is a questionnaire that could be very useful to assess pregnancy-specific stress, due to its good psychometric properties, which are higher than its previous version, the PDQ. It is essential to assess pregnancy-specific stress, as it could have negatives consequences in maternal and foetal health. By assessing it, it could be possible to detect pregnant women at risk and try to prevent those negatives consequences (Alderdice et al., 2012; Lobel et al., 2008). 


\section{References}

Alderdice, F., \& Lynn, F. (2009). Stress in pregnancy: Identifying and supporting women. British Journal of Midwifery, 17(9), 552-559.

http://www.scopus.com/inward/record.url?eid=2-s2.070350148175\&partnerID=tZOtx3y1

Alderdice, F., Lynn, F., \& Lobel, M. (2012). A review and psychometric evaluation of pregnancy-specific stress measures. Journal of Psychosomatic Obstetrics and Gynecology, 33(2), 62-77. https://doi.org/10.3109/0167482X.2012.673040

Caparros-Gonzalez, R.A., Romero-Gonzalez, B., Strivens-Vilchez, H., Gonzalez-Perez, R., Martinez-Augustin, O., \& Peralta-Ramirez, M. I. (2017). Hair cortisol levels, psychological stress and psychopathological symptoms as predictors of postpartum depression. PLoS ONE, 12(8), e0182817.

https://doi.org/10.1371/journal.pone.0182817

Caparros-Gonzalez, Rafael A., Perra, O., Alderdice, F., Lynn, F., Lobel, M., GarcíaGarcía, I., \& Peralta-Ramírez, M. I. (2019). Psychometric validation of the Prenatal Distress Questionnaire (PDQ) in pregnant women in Spain. Women and Health, 56, 1-16. https://doi.org/10.1080/03630242.2019.1584143

Cohen, S., Kamarck, T., \& Mermelstein, R. (1983). A global measure of perceived stress. Journal of Health Social Behavior, 24, 385-396 .

Connor, K. M., \& Davidson, J. R. T. (2003). Development of a new Resilience scale: The Connor-Davidson Resilience scale (CD-RISC). Depression and Anxiety, 18 , 76-82. https://doi.org/10.1002/da.10113 
Coussons-Read, M. E., Lobel, M., Carey, J. C., Kreither, M. O., D’Anna, K., Argys, L., et al. (2012). The occurrence of preterm delivery is linked to pregnancy-specific distress and elevated inflammatory markers across gestation. Brain, Behavior, and Immunity, 26(4), 650-659. https://doi.org/10.1016/j.bbi.2012.02.009

DiPietro, J. A., Ghera, M. M., Costigan, K., \& Hawkins, M. (2004). Measuring the ups and downs of pregnancy stress. Journal of Psychosomatic Obstetrics and Gynecology, 25(3-4), 189-201. https://doi.org/10.1080/01674820400017830

DiPietro, Janet A., Hilton, S. C., Hawkins, M., Costigan, K. A., \& Pressman, E. K. (2002). Maternal stress and affect influence fetal neurobehavioral development. Developmental psychology, 38(5), 659-668. https://doi.org/10.1037/00121649.38.5.659

Duthie, L., \& Reynolds, R. M. (2013). Changes in the maternal hypothalamic-pituitaryadrenal axis in pregnancy and postpartum: Influences on maternal and fetal outcomes. Neuroendocrinology, 98(2), 106-115. https://doi.org/10.1159/000354702

Epstein, J., Santo, R. M., \& Guillemin, F. (2015). A review of guidelines for crosscultural adaptation of questionnaires could not bring out a consensus. Journal of Clinical Epidemiology, 68(4), 435-441. https://doi.org/10.1016/j.jclinepi.2014.11.021

Field, T. (2010). Postpartum depression effects on early interactions, parenting, and safety practices: A review. Infant Behavior and Development, 33(1), 1-6. https://doi.org/10.1016/j.infbeh.2009.10.005 
García-León, M. A., Caparros-Gonzalez, R. A., Romero-Gonzalez, B., Gonzalez-Perez, R., \& Peralta-Ramirez, I. (2019). Resilience as a protective factor in pregnancy and puerperium: Its relationship with the psychological state, and with Hair Cortisol Concentrations. Midwifery, 75, 138-145. https://doi.org/10.1016/j.midw.2019.05.006

García-León, M. Á., González-Gómez, A., Robles-Ortega, H., Padilla, J. L., \& PeraltaRamírez, M. I. (2019). Psychometric properties of the connor-davidson resilience scale (CD-RISC) in the Spanish population. Anales de Psicologia, 35(1), 33-40. https://doi.org/10.6018/analesps.35.1.31411

González-Mesa, E., Kabukcuoglu, K., Körükcü, O., Blasco, M., Ibrahim, N., \& Kavas, T. (2018). Cultural factors influencing antenatal depression: A cross-sectional study in a cohort of Turkish and Spanish women at the beginning of the pregnancy. Journal of Affective Disorders, 238, 256-260. https://doi.org/10.1016/j.jad.2018.06.003

Graignic-Philippe, R., Dayan, J., Chokron, S., Jacquet, A. Y., \& Tordjman, S. (2014). Effects of prenatal stress on fetal and child development: A critical literature review. Neuroscience and Biobehavioral Reviews, 43, 137-162. https://doi.org/10.1016/j.neubiorev.2014.03.022

Gurman, T. A., \& Becker, D. (2008). Factors affecting latina immigrants' perceptions of maternal health care: Findings from a qualitative study. Health Care for Women International, 29(5), 507-526. https://doi.org/10.1080/07399330801949608

Lobel, M. (1996). The revised pregnancy distress questionnaire (NuPDQ). Stony Brook (NY): State University of New York at Stony Brook. 
Lobel, M., Cannella, D. L., Graham, J. E., DeVincent, C., Schneider, J., \& Meyer, B. a. (2008). Pregnancy-specific stress, prenatal health behaviors, and birth outcomes. Health psychology, 27(5), 604-615. https://doi.org/10.1037/a0013242

Lobel, M., Dunkel Schetter, C. (2016). Pregnancy and Prenatal Stress. In H. S. Friedman (Ed.), Encyclopedia of mental health (pp. 318-329). Waltham, Massachusetts: Academic Press.

Magriples, U., Kershaw, T. S., Rising, S. S., Massey, Z., \& Ickovics, J. R. (2008). Prenatal health care beyond the obstetrics service: Utilization and predictors of unscheduled care. American Journal of Obstetrics and Gynecology, 198(1), 1-7. https://doi.org/10.1016/j.ajog.2007.05.040

Martin, C. R., \& Savage-McGlynn, E. (2013). A 'good practice' guide for the reporting of design and analysis for psychometric evaluation. Journal of Reproductive and Infant Psychology, 31(5), 449-455. https://doi.org/10.1080/02646838.2013.835036

Nast, I., Bolten, M., Meinlschmidt, G., \& Hellhammer, D. H. (2013). How to measure prenatal stress? A systematic review of psychometric instruments to assess psychosocial stress during pregnancy. Paediatric and Perinatal Epidemiology, 27(4), 313-322. https://doi.org/10.1111/ppe.12051

Remor, E. (2006). Psychometric Properties of a European Spanish Version of the Perceived Stress Scale (PSS). The Spanish journal of psychology, 9(1), 86-93. https://doi.org/10.1017/S1138741600006004

Robertson, E., Grace, S., Wallington, T., \& Stewart, D. E. (2004). Antenatal risk factors for postpartum depression: A synthesis of recent literature. General Hospital 
Psychiatry, 26(4), 289-295. https://doi.org/10.1016/j.genhosppsych.2004.02.006

Roesch, S. C., Schetter, C. D., Woo, G., \& Hobel, C. J. (2004). Modeling the types and timing of stress in pregnancy. Anxiety, Stress and Coping, 17(1), 87-102. https://doi.org/10.1080/1061580031000123667

Romero-Gonzalez, B., Caparros-Gonzalez, R. A., Gonzalez-Perez, R., Delgado-Puertas, P., \& Peralta-Ramirez, M. I. (2018). Newborn infants' hair cortisol levels reflect chronic maternal stress during pregnancy. PLoS ONE, 13(7), e0200279. https://doi.org/10.1371/journal.pone.0200279

Romero-Gonzalez, Borja, Caparros-Gonzalez, R. A., Gonzalez-Perez, R., Coca-Arco, S., \& Peralta-Ramirez, M. I. (2019). Hair cortisol levels, psychological stress and psychopathological symptoms prior to instrumental deliveries. Midwifery, 77, 4552. https://doi.org/10.1016/j.midw.2019.06.015

Rosenthal, L., \& Lobel, M. (2018). Gendered racism and the sexual and reproductive health of Black and Latina Women. Ethnicity and Health, 1-26. https://doi.org/10.1080/13557858.2018.1439896

Staneva, A. A., Morawska, A., Bogossian, F., \& Wittkowski, A. (2018). Maternal psychological distress during pregnancy does not increase the risk for adverse birth outcomes. Women and Health, 58(1), 92-111. https://doi.org/10.1080/03630242.2017.1282395

Staneva, A., Morawska, A., Bogossian, F., \& Wittkowski, A. (2016). Pregnancyspecific distress: the role of maternal sense of coherence and antenatal mothering orientations. Journal of Mental Health, 25(5), 387-394. 
https://doi.org/10.3109/09638237.2015.1101425

Volling, B. L. (2012). Family transitions following the birth of a sibling: An empirical review of changes in the firstborn's adjustment. Psychological Bulletin, 138(3), 497-528. https://doi.org/10.1037/a0026921

Yali, A. M., \& Lobel, M. (1999). Coping and distress in pregnancy: An investigation of medically high risk women. Journal of Psychosomatic Obstetrics and Gynaecology, 20(1), 39-52. https://doi.org/10.3109/01674829909075575

Yali, A. M., \& Lobel, M. (2002). Stress-resistance resources and coping in pregnancy. Anxiety, Stress and Coping, 15(3), 289-309. https://doi.org/10.1080/1061580021000020743

Yüksel, F., Akin, S., \& Durna, Z. (2011). Prenatal Distres Ölçeği’ nin Türkçe’ye Uyarlanması ve Faktör Analizi. Hemşirelikte Eğitim ve Araştırma Dergisi, 8(3), $43-51$.

Table 1. Descriptive information of the sample

\begin{tabular}{|c|c|c|c|}
\hline & & M(SD) & $\mathbf{n}(\%)$ \\
\hline \multicolumn{4}{|c|}{ Sociodemographic variables } \\
\hline Age & & $32.36(5.10)$ & \\
\hline \multirow[t]{2}{*}{ Marital status } & Single/divorced & & $15(4.2)$ \\
\hline & Married/cohabitant & & $342(95.8)$ \\
\hline \multirow[t]{3}{*}{ Level of education } & Primary & & $12(3.4)$ \\
\hline & Secondary & & $101(28.3)$ \\
\hline & University & & $244(68.3)$ \\
\hline
\end{tabular}




\begin{tabular}{lll}
\hline Obstetric information & & \\
\hline Trimester of pregnancy & First & $70(19.2)$ \\
& Second & $135(37)$ \\
& Third & $160(43.8)$ \\
Pregnancy method & Spontaneous & $309(86.6)$ \\
& Fertility treatment & $48(13.4)$ \\
Nulliparous & Yes & $239(66.9)$ \\
& No & $118(33.1)$ \\
Wanted pregnancy & Yes & $306(85.7)$ \\
Previous children & No & $51(14.3)$ \\
& 0 & $265(74.2)$ \\
Previous miscarriages & 1 & $75(21)$ \\
& $\geq 2$ & $17(4.8)$ \\
& 0 & $261(73.1)$ \\
\hline
\end{tabular}

Note: Sociodemographic and obstetric information missing $(\mathrm{n}=5$ for trimester of pregnancy; $\mathrm{n}=13$ for the rest variables)

Table 2. Correlation between the NuPDQ total score and PDQ, PSS and CD-RISC total score

\begin{tabular}{lllll}
\hline Scale & NuPDQ & PDQ & PSS & CD-RISC \\
\hline NuPDQ & & .69 & .46 & -.28 \\
PDQ & & .43 & -.32 \\
PSS & & & -.40 \\
CD-RISC & & & \\
\hline
\end{tabular}

Note: all correlations significant at $p<0.001$. 
Table 3. Factor loadings of NuPDQ following exploratory factor analysis with maximumlikelihood estimation and oblique rotation.

\begin{tabular}{lccccc}
\hline Item & Factor 1 & Factor 2 & Factor 3 & Factor 4 & Factor 5 \\
\hline 1. & 0.20 & 0.20 & 0.17 & 0.15 & -0.19 \\
2. & 0.06 & $\mathbf{0 . 3 0}$ & 0.01 & -0.05 & 0.25
\end{tabular}




\begin{tabular}{llllll} 
3. & -0.05 & $\mathbf{0 . 6 5}$ & 0.03 & 0.08 & 0.07 \\
4. & $\mathbf{0 . 6 8}$ & 0.02 & 0.00 & 0.11 & -0.12 \\
5. & 0.12 & 0.21 & -0.01 & $\mathbf{0 . 4 1}$ & -0.14 \\
6. & 0.14 & 0.21 & 0.03 & 0.01 & $\mathbf{0 . 3 8}$ \\
7. & 0.04 & $\mathbf{0 . 7 2}$ & -0.06 & -0.05 & -0.02 \\
8. & 0.11 & 0.14 & 0.03 & 0.22 & $\mathbf{0 . 4 1}$ \\
9. & -0.08 & 0.04 & 0.07 & $\mathbf{0 . 4 2}$ & 0.16 \\
10. & $\mathbf{0 . 3 0}$ & 0.00 & 0.07 & 0.10 & $\mathbf{0 . 3 1}$ \\
11. & $\mathbf{0 . 9 0}$ & -0.01 & 0.01 & -0.05 & 0.06 \\
12. & 0.04 & $\mathbf{0 . 3 8}$ & 0.26 & 0.04 & 0.11 \\
13. & 0.04 & 0.14 & 0.18 & $\mathbf{0 . 3 9}$ & -0.03 \\
14. & 0.01 & -0.04 & $\mathbf{0 . 9 6}$ & -0.04 & 0.00 \\
15. & 0.00 & 0.14 & $\mathbf{0 . 5 5}$ & 0.20 & 0.01 \\
16. & 0.05 & -0.16 & -0.06 & $\mathbf{0 . 4 6}$ & 0.17 \\
17. & 0.02 & 0.13 & 0.02 & -0.09 & 0.14 \\
\hline
\end{tabular}


Table 4. Items description and factors name.

\begin{tabular}{|c|c|c|c|}
\hline Item & $\begin{array}{l}\text { Item description. } \\
\text { Are you feeling bothered, upset, or worried at this point in your pregnancy: }\end{array}$ & Factor & Proposed factor name \\
\hline $\begin{array}{c}4 \\
11\end{array}$ & $\begin{array}{l}\text { about pain during labor and delivery? } \\
\text { about what will happen during labor and delivery? }\end{array}$ & 1 & Worries about delivery \\
\hline $\begin{array}{l}2 \\
3 \\
7 \\
12\end{array}$ & $\begin{array}{l}\text { about the effect of ongoing health problems such as high blood pressure or diabetes on your pregnancy? } \\
\text { about feeling tired and having low energy during your pregnancy? } \\
\text { about physical symptoms of pregnancy such as vomiting, swollen feet, or backaches? } \\
\text { about working or caring for your family during your pregnancy? }\end{array}$ & 2 & Worries about own health and pregnancy \\
\hline $\begin{array}{l}14 \\
15\end{array}$ & $\begin{array}{l}\text { about working at a job after the baby comes? } \\
\text { about getting day care, babysitters, or other help to watch the baby after it comes? }\end{array}$ & 3 & Worries about taking care of the baby \\
\hline $\begin{array}{l}5 \\
9 \\
13 \\
16\end{array}$ & $\begin{array}{l}\text { about changes in your weight and body shape during pregnancy? } \\
\text { about changes in your relationships with other people due to having a baby? } \\
\text { about paying for the baby's clothes, food, or medical care? } \\
\text { about whether the baby might be affected by alcohol, cigarettes, or drugs that you have taken? }\end{array}$ & 4 & $\begin{array}{l}\text { Worries about physical, social and economic } \\
\text { changes }\end{array}$ \\
\hline $\begin{array}{l}6 \\
8\end{array}$ & $\begin{array}{l}\text { about whether the baby might come too early? } \\
\text { about the quality of your medical care during pregnancy? }\end{array}$ & 5 & $\begin{array}{l}\text { Worries about unexpected and incontrollable } \\
\text { issues of pregnancy }\end{array}$ \\
\hline Remove & & & \\
\hline $\begin{array}{c}1 \\
10 \\
17\end{array}$ & $\begin{array}{l}\text { about taking care of a newborn baby? } \\
\text { about whether you might have an unhealthy baby? } \\
\text { Are there other things that you are bothered, upset, or worried about that have to do with your } \\
\text { pregnancy, the birth, or the baby? }\end{array}$ & $\begin{array}{c}\text { none } \\
1 \text { and } 5 \\
\text { none }\end{array}$ & \\
\hline
\end{tabular}


Table 5. Correlations between the EFA-derived fourteen item NuPDQ sub-scales

\begin{tabular}{lllllll}
\hline Sub-scale & $\mathbf{1}$ & $\mathbf{2}$ & $\mathbf{3}$ & $\mathbf{4}$ & $\mathbf{5}$ & Total \\
\hline $\mathbf{1}$ & .34 & .27 & .32 & .36 & .62 \\
$\mathbf{2}$ & & .36 & .40 & .47 & .79 \\
$\mathbf{3}$ & & & .39 & .29 & .65 \\
$\mathbf{4}$ & & & & .41 & .74 \\
$\mathbf{5}$ & & & & & .69 \\
Total & & & & & & \\
\hline
\end{tabular}

Note: all correlations significant at $p<0.001$. 
Table 6. Comparison of 14-item EFA-derived NuPDQ total score and EFA-derived sub-scales as a function previous pregnancies status (degrees of freedom $=355$ )

\begin{tabular}{ccccc}
\hline Scale & $\begin{array}{c}\text { No previous pregnancy } \\
\mathbf{n = 1 1 8} \\
\mathbf{M}(\mathbf{S D})\end{array}$ & $\begin{array}{c}\text { Previous pregnancy } \\
\mathbf{n = 2 3 9} \\
\mathbf{M}(\mathbf{S D})\end{array}$ & $\boldsymbol{t}$ & $\boldsymbol{p}$ \\
\hline $\mathbf{1}$ & $1.18(1.11)$ & $2.28(1.25)$ & 2.96 & 0.003 \\
$\mathbf{2}$ & $3.11(1.90)$ & $3.03(2.08)$ & 0.36 & 0.72 \\
$\mathbf{3}$ & $1.84(1.46)$ & $1.86(1.37)$ & 0.15 & 0.88 \\
$\mathbf{4}$ & $1.75(1.53)$ & $2.33(1.75)$ & 3.04 & 0.003 \\
$\mathbf{5}$ & $1.58(1.17)$ & $1.70(1.23)$ & 0.87 & 0.39 \\
Total & $10.17(4.85)$ & $11.21(5.53)$ & 1.74 & 0.08 \\
\hline
\end{tabular}

Note: discrepancy between group $\mathrm{N}$ and total sample size due to small amount of missing data on regarding previous pregnancy status. 
Table 7. Correlations between 14-item EFA-derived NuPDQ total score and EFA-derived sub-scales and PDQ, PSS and CD-RISC.

\begin{tabular}{lccc}
\hline Sub-scale & PDQ & PSS & CD-RISC \\
\hline $\mathbf{1 .}$ & .52 & .22 & -.31 \\
$\mathbf{2 .}$ & .50 & .44 & -.19 \\
$\mathbf{3 .}$ & .40 & .19 & -.08 \\
$\mathbf{4 .}$ & .57 & .38 & -.25 \\
$\mathbf{5 .}$ & .45 & .31 & -.14 \\
Total & .69 & .46 & -.28 \\
\hline
\end{tabular}

